\title{
Mechanical Properties of Ti-50(Pt,Ir) High-Temperature Shape Memory Alloys
}

\author{
Yoko Yamabe-Mitarai ${ }^{1}$, Toru Hara ${ }^{1}$, Seiji Miura ${ }^{2}$ and Hideki Hosoda ${ }^{3}$ \\ ${ }^{1}$ National Institute for Material Science, Tsukuba 305-0047, Japan \\ ${ }^{2}$ Materials and Process Design Division of Materials Science and Engineering, Hokkaido University, \\ Sapporo 060-0813, Japan \\ ${ }^{3}$ Precision \& Intelligence Laboratory (P\&I Lab.), Tokyo Institute of Technology, Yokohama 226-8503, Japan
}

To develop high-temperature shape memory alloys, Ti-50(Pt,Ir)mol\% compounds are noted because of their martensitic transformation from $\mathrm{B} 2$ to $\mathrm{B} 19(2 \mathrm{H})$ or $4 \mathrm{H}(4 \mathrm{O})$ structures above $1273 \mathrm{~K}$. A thermal expansion measurement and loading-unloading compression test were performed for $\mathrm{Ti}-50(\mathrm{Pt}$,Ir) to determine if the shape memory effect or superelasticity was shown. The thermal expansion measurement indicated the shape recovery in some of the compounds. The maximum shape recovery was about $4 \%$ by reheating at the above martensite transformation temperature after a loading-unloading compression test. Superelasticity was also observed in ternary compounds. The potential of Ti-50(Pt,Ir) as a high-temperature shape memory alloy is discussed.

(Received August 22, 2005; Accepted November 7, 2005; Published March 15, 2006)

Keywords: high-temperature shape memory alloys, TiPt, TiIr, B2, B19, martensitic transformation

\section{Introduction}

Applications of high-temperature shape memory alloys for gas turbines, rocket engines, automotive engines, and nuclear reactor environments can be envisioned. However, only a limited number of alloys have potential as high-temperature shape memory alloys. Some of those are NiAl [for example Ref. 1)], $\mathrm{Ti}(\mathrm{Ni}, \mathrm{Pt}),{ }^{2-4)} \mathrm{Ti}(\mathrm{Ni}, \mathrm{Pd}),{ }^{5-10)}$ and $\mathrm{RuX}(\mathrm{X}=\mathrm{Ta}$, $\mathrm{Nb}){ }^{11,12)}$ Among them, the martensitic temperature related to the shape memory effect exceeds $1273 \mathrm{~K}$ in only TiPt and $\mathrm{RuX}(\mathrm{X}=\mathrm{Ta}, \mathrm{Nb})$. Intermetallics, including platinum group metals (PGMs), have been noted as high-temperature shape memory alloys that can work above $1273 \mathrm{~K}$. The hightemperature $\beta$ phase with an ordered B2 structure transforms to the distorted tetragonal phase, the $\beta^{\prime}$ phase, in RuTa and RuNb. ${ }^{13,14)}$ Upon further cooling, an additional transformation to the monoclinic $\beta^{\prime \prime}$ phase occurs. ${ }^{15)}$ The equiatomic compositions of RuTa and RuNb indicated a highly twinned microstructure, and the bended samples showed 5 or $4 \%$ shape recoveries at the tensile surface. ${ }^{11)}$ The high-temperature-ordered cuboidal B2 phase has been reported to transform to the orthrombic B19 phase in TiPt. ${ }^{16,17)}$ The investigation of the phase transformation in TiPt suggested a martensitic transformation and its high potential as a hightemperature shape memory alloy. ${ }^{18,19)}$

As shown above, some intermetallics, including PGMs, show a high martensitic transformation temperature. However, there is very limited research on these intermetallics. In a previous study, we investigated the phase transformation of Ir-added TiPt. ${ }^{20}$ The addition of Ir to TiPt is expected to increase the martensitic transformation temperature of TiPt because, as has been reported, Ir-rich TiIr also transforms from the B2 phase to the low-temperature phase above $1873 \mathrm{~K}$, although the phase structure at low temperature is still under debate. ${ }^{16,17)}$ Ternary Ti-50(Pt,Ir) compounds also have a phase transformation from the high-temperature phase to the low-temperature phase. The low-temperature phase of Ti-12.5Pt-37.5Ir alloy was investigated and revealed that the low temperature phase is composed of the mixture of B19 $(2 \mathrm{H})$ and $4 \mathrm{H}$ structures. ${ }^{21)}$ It has the possibility that the ternary systems of other compositions are not simple B19(2H) structure. By the addition of Ir, the phase transformation temperature increased from 1323 to $1423 \mathrm{~K}$, as expected. ${ }^{20)}$ The surface relief of Ti-50(Pt,Ir) observed using a confocal scanning laser microscope suggested that this phase transformation is also a martensitic transformation. ${ }^{22}$ )

In this study, the mechanical properties of TiPt and Ti$50(\mathrm{Pt}, \mathrm{Ir})$, such as the shape memory effect or superelasticity, were investigated using a high-temperature loading-unloading compression test and a thermal expansion measurement. The potential of these compounds as high-temperature shape memory alloys is discussed.

\section{Experimental Procedure}

Fifteen-gram alloy ingots with a nominal composition of Ti-50Pt, Ti-37.5Pt-12.5Ir, Ti-25Pt-25Ir, and Ti-12.5Pt37.5Ir $(\mathrm{mol} \%)$ were prepared by the arc melting method. Samples with sizes of $3 \times 3 \times 8$ and $3 \times 3 \times 6 \mathrm{~mm}$ were cut from the alloy ingots for the thermal expansion measurement and the compression test, respectively. Cylindrical samples with a diameter of $3 \mathrm{~mm}$ and a length of $4 \mathrm{~mm}$ were also cut for the microstructure observation under transmission electron microscopy. These samples were sealed together in a vacuum with a small amount of Ar gas in a silica tube and heat-treated at $1523 \mathrm{~K}$, a higher temperature than the transformation temperature of all tested alloys for $24 \mathrm{~h}$ in the furnace; this was followed by ice water quenching.

The thermal expansion measurement was performed for non-deformed and deformed samples using a dilatometer (Rigaku dilatometer TMA8140C). Deformation was conducted until the reorientation of martensite variants occurred. The temperature was measured and controlled by a Pt/Pt13 at\% Rh thermocouple inserted in a blind hole in a reference alumina sample. Thermal expansion tests were conducted over the temperature range from 300 up to $1600 \mathrm{~K}$ at a heating rate of $0.167 \mathrm{~K} / \mathrm{s}$ in an Ar atmosphere.

The loading-unloading compression test was carried out at temperatures below the Martensitic transformation start temperature $\left(M_{\mathrm{s}}\right)$, between the Austenite transformation start 

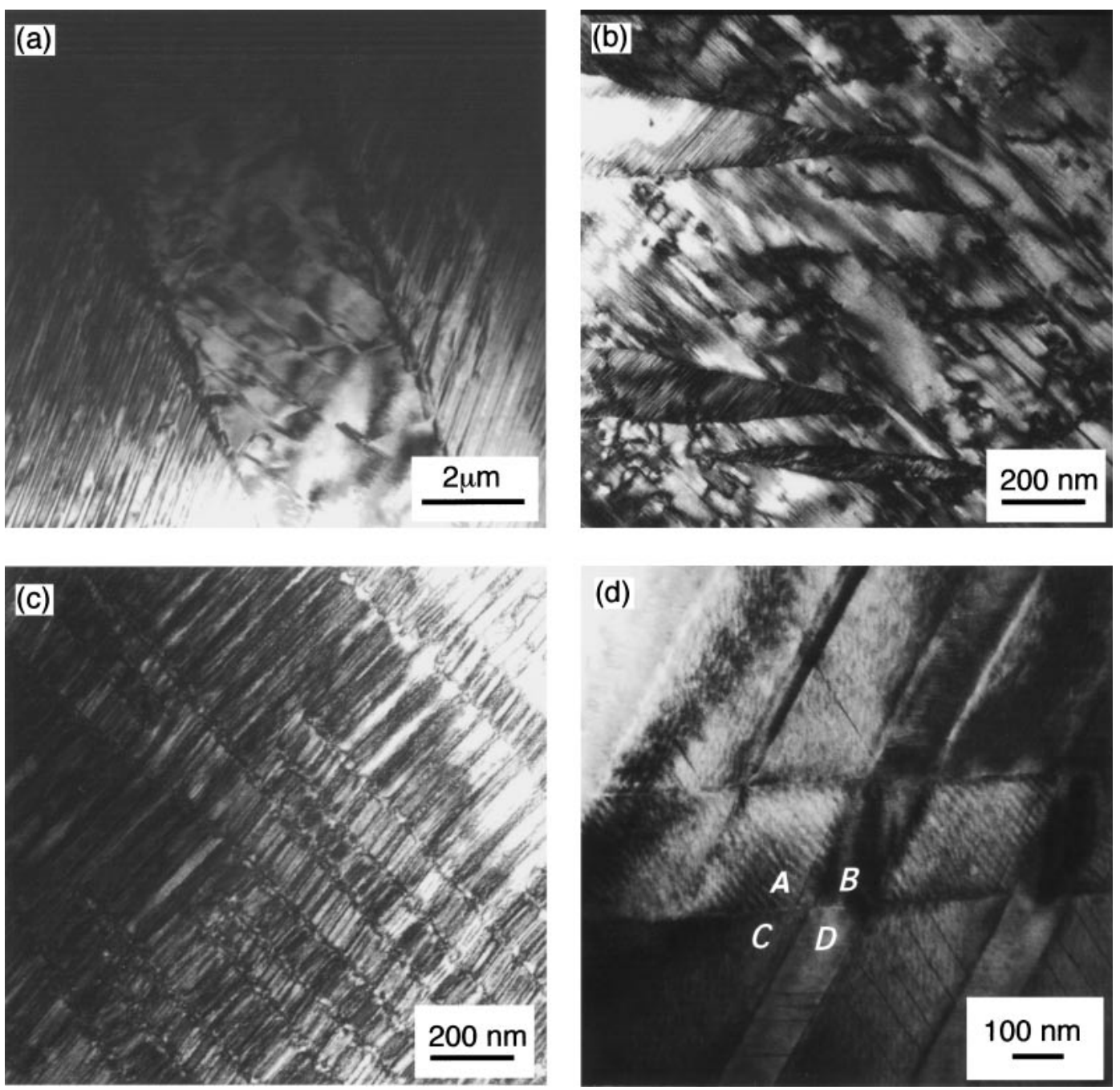

Fig. 1 Typical microstructure of (a) Ti-50Pt, (b) Ti-37.5Pt-12.5Ir, (c) Ti-25Pt-25Ir, and (d) Ti-12.5Pt-37.5Ir heat-treated at $1523 \mathrm{~K}$ for $24 \mathrm{~h}$ followed by ice water quenching.

Table 1 Phase transformation temperature of Ti-50Pt and Ti-50(Pt,Ir) determined by the DTA $(\mathrm{K})$.

\begin{tabular}{lcccc}
\hline & $A_{\mathrm{s}}$ & $A_{\mathrm{f}}$ & $M_{\mathrm{s}}$ & $M_{\mathrm{f}}$ \\
\hline Ti-50Pt & 1273 & 1330 & 1262 & 1236 \\
Ti-37.5Pt-12.5Ir & 1309 & 1376 & 1273 & 1251 \\
Ti-25Pt-25Ir & 1394 & 1463 & 1383 & 1341 \\
Ti-12.5Pt-37.5Ir & 1448 & 1491 & 1457 & 1442 \\
\hline
\end{tabular}

temperature $\left(A_{\mathrm{s}}\right)$ and the Austenite transformation finish temperature $\left(A_{\mathrm{f}}\right)$, and above $A_{\mathrm{f}}$ with an initial strain rate of $3 \times 10^{-4} / \mathrm{s}$ in Shimadzu AG-I. To investigate the shape memory effect, the sample was cooled down to room temperature from the testing temperature after the compression test was performed, and the sample length was measured. Then, the sample was again heated above the phase transformation temperature in the high-temperature furnace. The final sample length was measured after quenching.

Sliced samples with a thickness of $0.2 \mathrm{~mm}$ were cut from heat-treated cylindrical samples with a diameter of $3 \mathrm{~mm}$. The sliced samples were polished mechanically with $\mathrm{SiC}$ paper, dimpled, and then ion-milled. The microstructures of

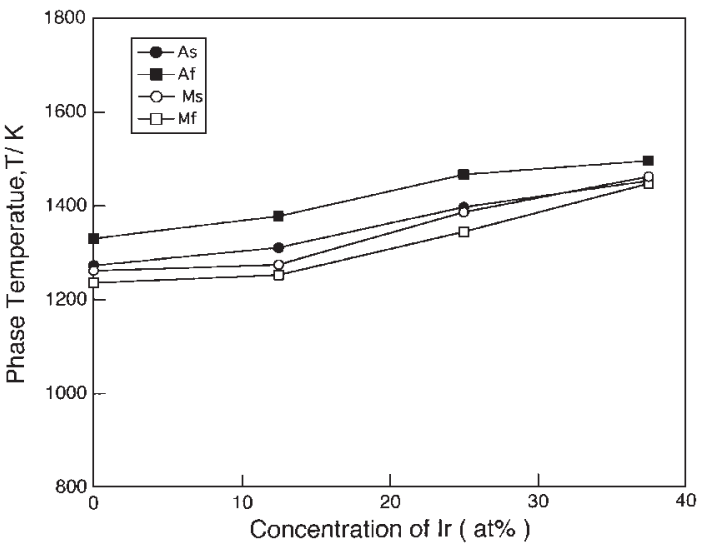

Fig. 2 Phase transformation temperature as a function of the Ir concentration.

these heat-treated samples were observed using Philips CM200 transmission electron microscopy (TEM).

\section{Results}

The typical microstructures of Ti-50(Pt,Ir) are shown in 

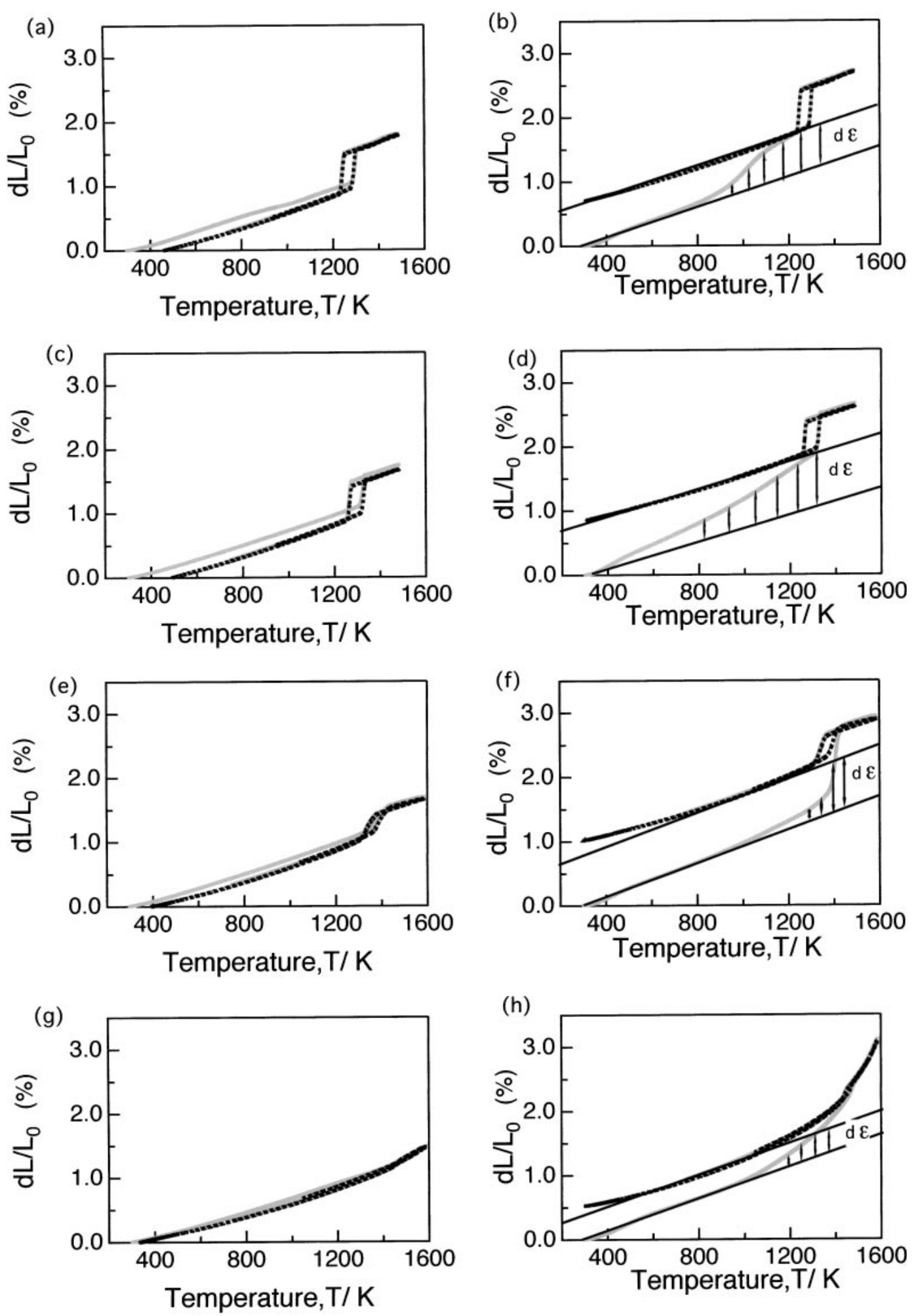

Fig. 3 Thermal expansion behavior of (a, b) Ti-50Pt, (c, d) Ti-37.5Pt-12.5Ir, (e, f) Ti-25Pt-25Ir, and (g, h) Ti-12.5Pt-37.5Ir. The lefthand-side figures ( $\mathrm{a}, \mathrm{c}, \mathrm{e}, \mathrm{g})$ show the thermal expansion behavior of non-deformed samples, while the right-hand-side figures (b, $\mathrm{d}, \mathrm{f}, \mathrm{h}$ ) show the thermal expansion behavior of deformed samples. The first and second cycles are represented by gray and dotted lines, respectively.

Fig. 1. All compounds exhibited a highly twinned microstructure. This twined microstructure consists of coarse twins with various widths depending on the alloy composition and the observed area. Each coarse twin has a finely twinned internal structure. In the compounds with high Ir contents, twins intersected in two directions, and then different types of twin interfaces appeared [Figs. 1(c) and (d)]. For example, areas $\mathrm{A}$ and $\mathrm{B}, \mathrm{B}$ and $\mathrm{C}, \mathrm{C}$ and $\mathrm{D}$, and $\mathrm{D}$ and $\mathrm{A}$ have a twin relationship in Ti-12.5Pt-37.5Ir [Fig. 1(d)]. ${ }^{21)}$ Judging from diffraction patterns, most of finely induced twin is Type I twin which is mirror-related to each side of crystals. Coarsely induced compound twin is also found, for example, shown in 
Fig. 1(b). Twinning morphology in these alloys is typical one that was often observed in thermoelastically transformed martensite.

Before the mechanical properties are shown, details of the martensitic transformation temperature investigated using differential thermal analysis are presented in Table 1 and Fig. 2 because only the average transformation temperatures, $A^{*}$ and $M^{*}$, were shown in our previous paper; ${ }^{20)}$ taking those parameters into account, the testing condition was decided. $A_{\mathrm{s}}, A_{\mathrm{f}}, M_{\mathrm{s}}$, and the Martensitic transformation finish temperature $\left(M_{\mathrm{f}}\right)$ are plotted as a function of the concentration of Ir in Fig. 2. All transformation temperatures increased with increasing Ir contents, while the temperature difference between $M_{\mathrm{s}}$ and $A_{\mathrm{s}}$ decreased with increasing Ir contents.

The thermal expansion behaviors of $\mathrm{Ti}-50(\mathrm{Pt}, \mathrm{Ir})$ are shown in Fig. 3. The left-hand-side diagrams, Figs. 3(a), (c), (e), and (g), indicate the thermal expansion behavior of non-deformed samples. The non-deformed samples gradually expanded with increasing temperature and shrank with decreasing temperature, expect for the one discontinuous length change. The expansion and shrinkage behavior were almost the same in the first and second cycles. The discontinuous length change was accompanied with the phase transformation because the transformation temperature

Table 2 Shape recovery of $\mathrm{Ti}-50 \mathrm{Pt}$ and $\mathrm{Ti}-50(\mathrm{Pt}$, Ir) investigated using the thermal expansion test.

\begin{tabular}{lc}
\hline & Shape recovery $(\%)$ \\
\hline Ti-50Pt & 0.6 \\
Ti-37.5Pt-12.5Ir & 0.9 \\
Ti-25Pt-25Ir & 0.9 \\
Ti-12.5Pt-37.5Ir & 0.4 \\
\hline
\end{tabular}

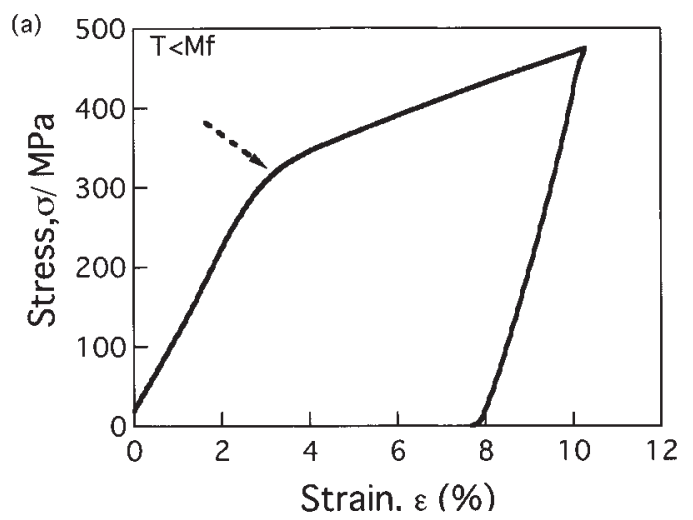

(c)

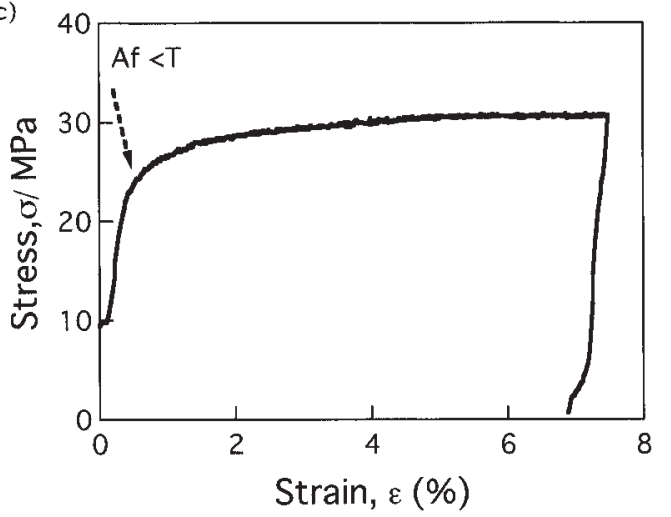

observed in the thermal expansion measurement was almost consistent with the phase transformation determined by the DTA. This change was very clear in TiPt and Ti-37.5Pt12.5Ir (Figs. 3(a) and (c), respectively) but became small and was not clear in $\mathrm{Ti}-25 \mathrm{Pt}-25 \mathrm{Ir}$ and $\mathrm{Ti}-12.5 \mathrm{Pt}-37.5 \mathrm{Ir}$ [Figs. 3(e) and (g), respectively]. This behavior is consistent with the DTA curves in our previous study. ${ }^{20)}$ The peaks corresponding to the phase transformation in the DTA curves were very strong and sharp in TiPt and Ti-37.5Pt-12.5Ir, but those in $\mathrm{Ti}-25 \mathrm{Pt}-25 \mathrm{Ir}$ and $\mathrm{Ti}-12.5 \mathrm{Pt}-37.5 \mathrm{Ir}$ were very weak and broad in the DTA curves. The right-hand-side diagrams, Figs. 3(b), (d), (f), and (h), show the thermal expansion behavior of the compressively deformed samples. Larger expansion than that in non-deformed samples was observed in all compounds. On the other hand, the shrinkage of compounds was smaller than the expansion. Furthermore, the expansion behavior in the second cycle was smaller than that

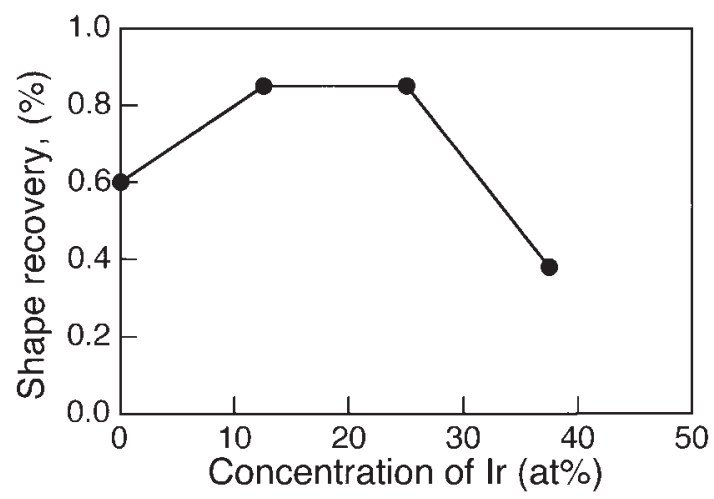

Fig. 4 Shape recovery of $\mathrm{Ti}-50 \mathrm{Pt}$ and $\mathrm{Ti}-50(\mathrm{Pt}, \mathrm{Ir})$ measured by the thermal expansion test.

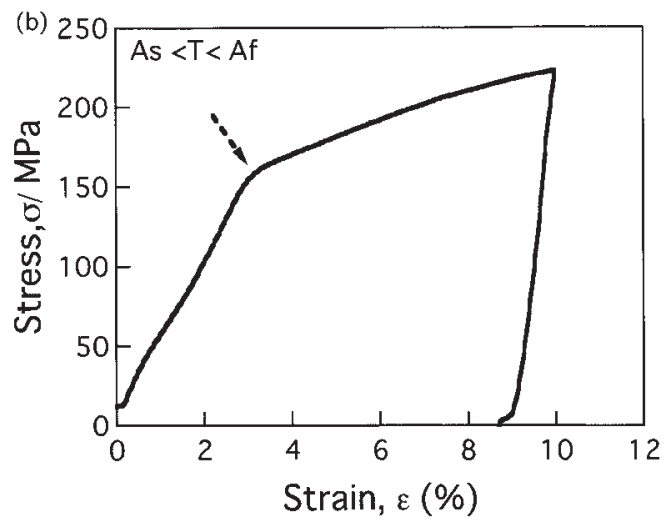

Fig. 5 Stress-strain curves of Ti-50Pt at (a) $1183 \mathrm{~K}$ under $M_{\mathrm{f}}$, (b) $1293 \mathrm{~K}$ between $A_{\mathrm{s}}$ and $A_{\mathrm{f}}$, and (c) $1373 \mathrm{~K}$ above $A_{\mathrm{f}}$. Dashed arrows indicate the $0.2 \%$ flow stress. 

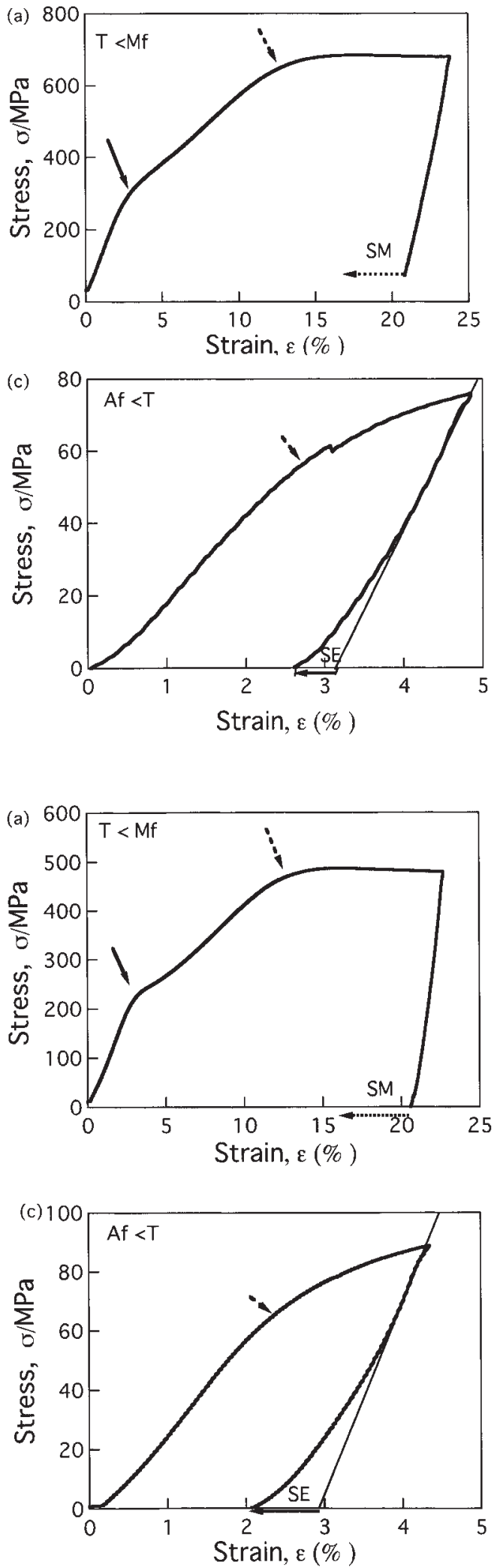

in the first cycle and almost the same as the shrinkage behavior in the first cycle. This indicates that the initial expansion in the first cycle corresponds to the shape recovery. In detail, the expansion behavior in the first cycle was different in each compound. For example, deformed TiPt started to show extra expansion, which was larger than non-deformed samples, i.e., around $800 \mathrm{~K}$ below the phase

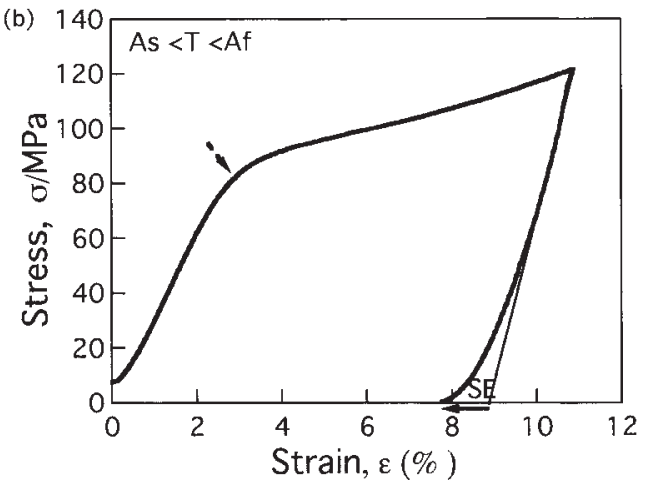

Fig. 6 Stress-strain curves of Ti-37.5Pt-12.5Ir at (a) $1201 \mathrm{~K}$ under $M_{\mathrm{f}}$, (b) $1342 \mathrm{~K}$ between $A_{\mathrm{s}}$ and $A_{\mathrm{f}}$, and (c) $1383 \mathrm{~K}$ above $A_{\mathrm{f}}$. The shape recovery by reheating above the phase transformation temperature and the superelasticity are represented by SM and SE, respectively. Dashed arrows indicate the $0.2 \%$ flow stress. An arrow in (a) indicates the stress of reorientation of the martensite variants.

(b)

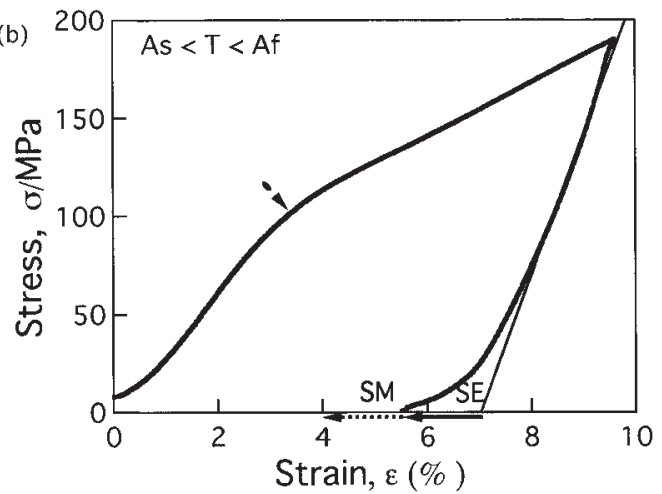

Fig. 7 Stress-strain curves of Ti-25Pt-25Ir at (a) $1291 \mathrm{~K}$ under $M_{\mathrm{f}}$, (b) $1428 \mathrm{~K}$ between $A_{\mathrm{s}}$ and $A_{\mathrm{f}}$, and (c) $1483 \mathrm{~K}$ above $A_{\mathrm{f}}$. The shape recovery by reheating above the phase transformation temperature and the superelasticity are represented by SM and SE, respectively. Dashed arrows indicate the $0.2 \%$ flow stress. An arrow in (a) indicates the stress of reorientation of the martensite variants.

transformation temperature. Ti-37.5Pt-12.5Ir and Ti12.5Pt-37.5Ir gradually showed extra expansion as well, which started from a lower temperature, around $400 \mathrm{~K}$, than that in TiPt. The reason for the gradual recovery below the phase transformation temperature is not clear. In Ti-25Pt25Ir, a large discontinuous expansion near the phase transformation was also observed. 

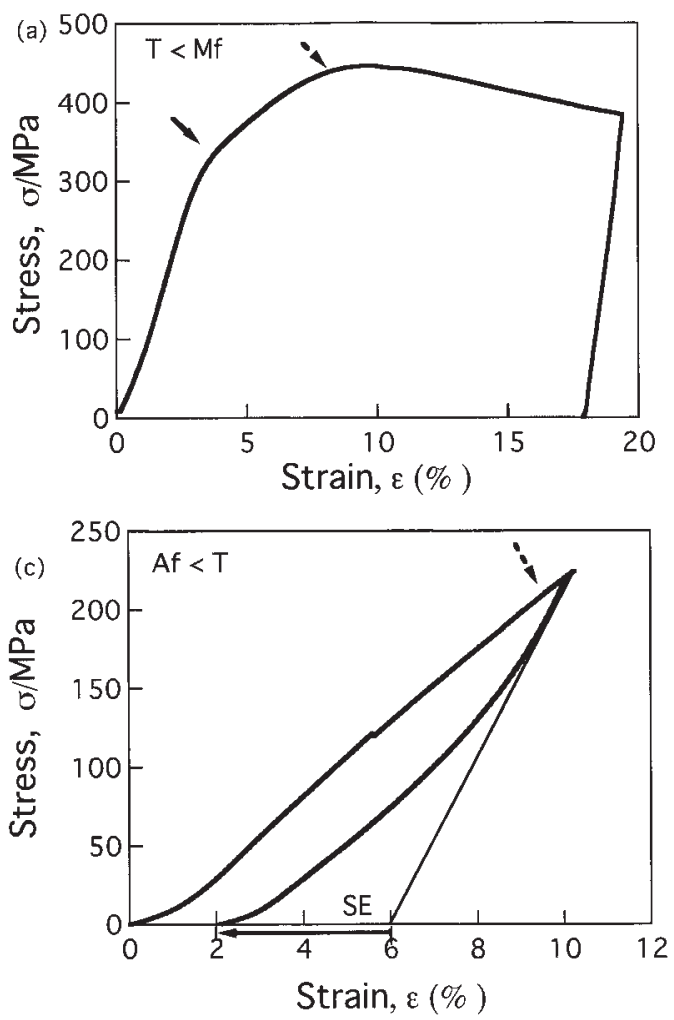

Table 3 Shape recovery by reheating after the loading-unloading compression test and superelasticity observed using the compression test during unloading above $A_{\mathrm{s}}$ in Ti-50Pt and Ti-50(Pt,Ir).

\begin{tabular}{lcc}
\hline & Shape recovery (\%) & Superelasticity (\%) \\
\hline Ti-50Pt & 0 & 0 \\
\hline Ti-37.5Pt-12.5Ir & $1201 \mathrm{~K}: 2.0$ & $1342 \mathrm{~K}: 1.3$ \\
& & $1383 \mathrm{~K}: 0.6$ \\
\hline Ti-25Pt-25Ir & $1291 \mathrm{~K}: 4.0$ & $1428 \mathrm{~K}: 1.7$ \\
& $1428 \mathrm{~K}: 1.8$ & $1483 \mathrm{~K}: 0.9$ \\
\hline Ti-12.5Pt-37.5Ir & $1392 \mathrm{~K}: 0$ & $1469 \mathrm{~K}: 1.9$ \\
& $1469 \mathrm{~K}: 2.0$ & $1503 \mathrm{~K}: 4.0$ \\
\hline
\end{tabular}

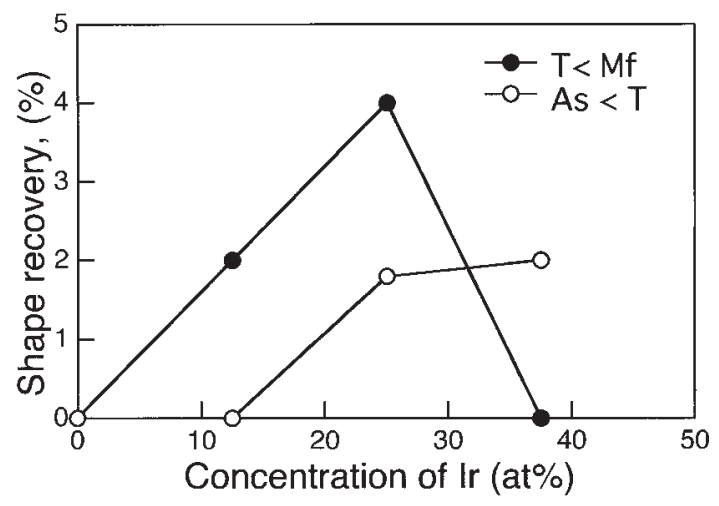

Fig. 9 Shape recovery of $\mathrm{Ti}-50 \mathrm{Pt}$ and $\mathrm{Ti}-50(\mathrm{Pt}$,Ir) measured by reheating above $A_{\mathrm{f}}$ after the loading-unloading compression test.

The shape recovery was estimated from the thermal expansion curves in Fig. 3. The estimated shape recovery is summarized in Table 2 and plotted in Fig. 4. The highest shape recovery, $0.85 \%$, was found in Ti-37.5Pt-12.5Ir and

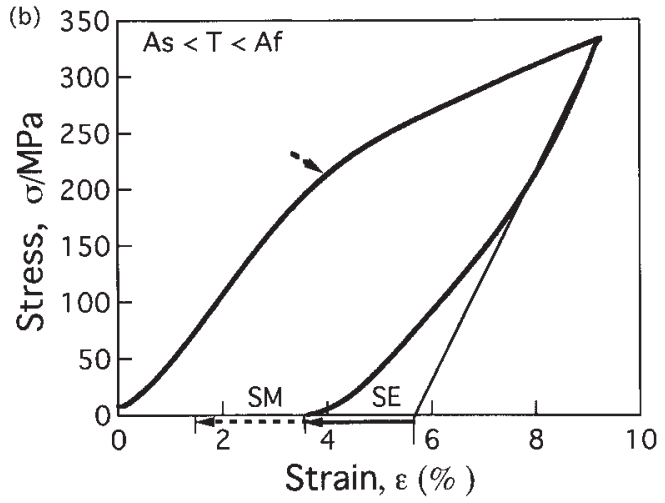

Fig. 8 Stress-strain curves of Ti-12.5Pt-37.5Ir at (a) $1392 \mathrm{~K}$ under $M_{\mathrm{f}}$, (b) $1469 \mathrm{~K}$ between $A_{\mathrm{s}}$ and $A_{\mathrm{f}}$, and (c) $1503 \mathrm{~K}$ above $A_{\mathrm{f}}$. The shape recovery by reheating above the phase transformation temperature and the superelasticity are represented by SM and SE, respectively. Dashed arrows indicate the $0.2 \%$ flow stress. An arrow in (a) indicates the stress of reorientation of the martensite variants.

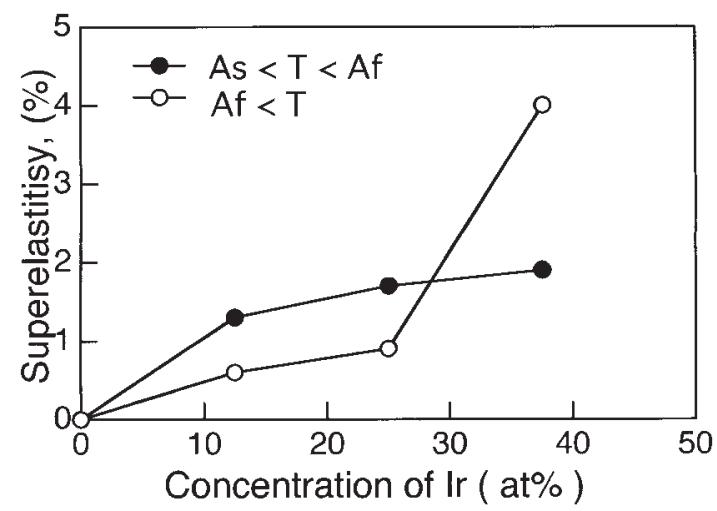

Fig. 10 Superelasticity of $\mathrm{Ti}-50 \mathrm{Pt}$ and $\mathrm{Ti}-50(\mathrm{Pt}$,Ir) measured by the loading-unloading compression test. The closed and open symbols represent the results at temperatures between $A_{\mathrm{s}}$ and $A_{\mathrm{f}}$ and above $A_{\mathrm{f}}$, respectively.

\section{Ti-25Pt-25Ir.}

The stress-strain curves of the loading-unloading compression test are shown from Figs. 5 to 8 . In Ti-50Pt, the reorientation of the martensite variants during elastic deformation, shape recovery by heat treatment above $A_{\mathrm{f}}$ after deformation, or superelasticity during unloading, these phenomena which are often observed in various shape memory alloys, was not clearly observed for the samples tested at various temperatures (Fig. 5). For Ti-37.5Pt-12.5Ir, the curvature change that corresponds to the reorientation of the martensite variants clearly appeared, as shown by an arrow under $M_{\mathrm{f}}$ [Fig. 6(a)]. Then, the stress shown by a dashed arrow is considered to be the critical stress of plastic deformation of the martensite phase. The shape recovery of $2 \%$ was found by heat treatment above $A_{\mathrm{f}}$ after deformation. At a temperature above $A_{\mathrm{s}}$, a small shape recovery was found 
during unloading [Figs. 6(b) and (c)]. This shape recovery is considered to be superelasticity by reverse transformation from martensite to parent phases. However, the incomplete superelastic strain indicates that plastic deformation also occurred during the test at temperatures above $A_{\mathrm{s}}$. The stressstrain curves of Ti-25Pt-25Ir are similar to those of Ti37.5Pt-12.5Ir (Fig. 7). Under $M_{\mathrm{f}}$, the reorientation of the martensite variants as shown by an arrow was clearly observed. Although plastic deformation occurred as shown by a dashed arrow, strain of $4 \%$, which is larger than that in Ti-37.5Pt-12.5Ir, was recovered [Fig. 7(a)]. One different result is that the shape recovery of $1.8 \%$ was clearly found by reheating $A_{\mathrm{f}}$ after the loading-unloading test at a temperature between $A_{\mathrm{s}}$ and $A_{\mathrm{f}}$ [Fig. 7(b)]. Superelasticity was also clearly found above $A_{\mathrm{s}}$ [Figs. 7(b) and (c)]. In Ti-12.5Pt37.5Ir, although the reorientation of the martensite variants was observed, shape recovery was not observed in the sample tested under $M_{\mathrm{f}}$ [Fig. 8(a)]. Shape recovery was identified in the sample tested between $A_{\mathrm{s}}$ and $A_{\mathrm{f}}$ [Figs. 8(a) and (b)]. Superelasticity clearly appeared above $A_{\mathrm{s}}$ in this compound [Figs. 8(b) and (c)]. No shape recovery under $M_{\mathrm{f}}$ and incomplete superelasticity indicates that plastic deformation occurred during the test. The shape recovery and superelasticity obtained with the loading-unloading compression test are summarized in Table 3 and plotted in Figs. 9 and 10, respectively. The highest shape recovery was obtained in Ti25Pt-25Ir tested below $M_{\mathrm{s}}$. On the other hand, among the samples tested above $A_{\mathrm{s}}$, the ternary compounds with Ir over $25 \mathrm{~mol} \%$ indicated a high shape recovery. The superelasticity increased with increasing Ir contents under both conditions, between $A_{\mathrm{s}}$ and $A_{\mathrm{f}}$ and above $A_{\mathrm{f}}$.

\section{Discussion}

The martensitic transformation from the B2 to B19 phases in TiPt is the same type as that in TiPd, whose $M_{\mathrm{s}}$ is at 823 , $500 \mathrm{~K}$ lower than that in TiPt. Good shape memory strain has been reported in Ti-50Pd at room temperature, but the recovery of strain decreased with increasing testing temperature and was finally lost. ${ }^{5}$ It is considered that the poor shape memory characteristics at high temperature were due to the rapid decrease of the critical stress for slip at high temperature. In the case of TiPt, no shape recovery was found at $1183 \mathrm{~K}$ by the loading-unloading compression test. Although the shape recovery after deformation at room temperature has not been investigated in TiPt yet, the thermal expansion measurement indicated a small shape recovery in TiPt. It is considered that the shape recovery of TiPt also shows temperature dependence. The $0.2 \%$ flow stress caused by plastic deformation and the stress of reorientation of martensite variants were estimated from the compressive stress-strain curves and are plotted in Fig. 11. As indicated in results, the critical stresses represented by a dashed arrow in Figs. 5-8 are caused by plastic deformation. This $0.2 \%$ flow stress are plotted by solid symbols in Fig. 11. In the some of the test conditions, the stress of reorientation of martensite variants shown by an arrow is clearly observed. The stress of reorientation of martensite variants is plotted by open symbols. The $0.2 \%$ flow stress of TiPt was the lowest among the tested compounds, and the $0.2 \%$ flow stress increased

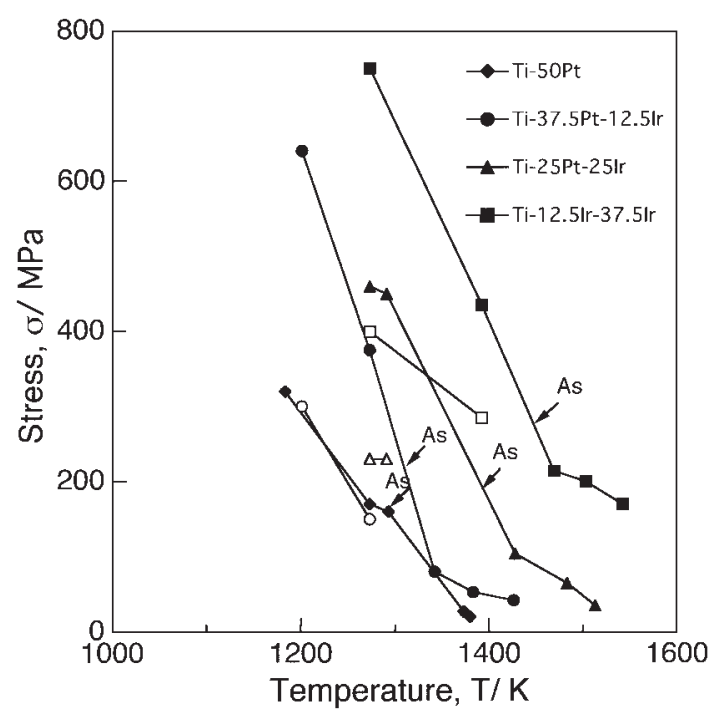

Fig. 11 Temperature dependence of the $0.2 \%$ flow stress (closed symbol) and stress for reorientation of martensite variants (open symbol) of Ti50Pt and Ti-50(Pt,Ir).

with increasing Ir contents. This suggests that the rapid decrease of the critical stress for slip caused the loss of the shape memory effect in TiPt at high temperature, as it happens in TiPd.

The poor shape recovery effect of TiPd was improved by expansion to the ternary $\mathrm{Ti}-\mathrm{Pd}-\mathrm{Ni}$ system as well as by attempting thermomechanical treatment or precipitation hardening by $\mathrm{TiB}_{2}$ for the ternary $\mathrm{Ti}-\mathrm{Pd}-\mathrm{Ni}$. In the case of TiPt, the ternary system by addition of Ir was investigated. Despite the lack of thermomechanical treatment or precipitation hardening, shape recovery and superelasticity were clearly observed in the ternary Ti-Pt-Ir. This indicates that the addition of Ir is effective to improve the shape memory effect and superelasticity of TiPt. Since there seemed to be no large difference in microstructure between $\mathrm{TiPt}$ and $\mathrm{Ti}-$ (Pt,Ir), as shown in Fig. 1, it is not clear if the microstructure change by Ir addition improved the shape memory effect. Further investigation is necessary to understand the Ir effect on the microstructure. Another advantage of the Ir addition is that it increases both the stress for reorientation of martensite variants and the $0.2 \%$ flow stress at high temperature, as shown in Fig. 11. This suggests that the critical stress due to the slip of dislocation increases by the addition of Ir at high temperature. This is because Ir is an element with a high melting temperature of about $2720 \mathrm{~K}$ that forms the B2 type structure with $\mathrm{Ti}$ at high temperature. Attempting on thermomechanical treatment and/or precipitation hardening is also effective for further improvement of the shape memory effect of Ti-Pt-Ir.

In ternary Ti-Pt-Ir compounds, although the $0.2 \%$ flow stress decreases with increasing temperature, the slope of the temperature-stress curve changed above $A_{\mathrm{s}}$ in Fig. 11. At a temperature above $A_{\mathrm{s}}$, both martensite and parent phases coexist since the martensite phase started to transform into the parent phase by the reverse martensitic transformation. However, stress-induced martensite is also formed during loading at this temperature. The flow stress was changed due to the coexistence of the two phases. 
As high-temperature shape memory alloys, RuTa or RuNb are very promising materials because of their high martensitic transformation temperature. In detail, both RuTa and $\mathrm{RuNb}$ have a B2 structure at high temperature and transform to a slightly distorted tetragonal structure. The tetragonal structure again tranformed into a monoclinic structure depending on the alloy composition. The transformation temperature depended on the $\mathrm{Ta}$ or $\mathrm{Nb}$ concentration. ${ }^{16,17)}$ The highest transformation occurred at 44 at $\%$ Ta at around $1627 \mathrm{~K}$ in RuTa and decreased to room temperature with increasing Ta concentration (up to 63). In the case of RuNb, the highest transformation temperature appeared at 45 at $\%$ $\mathrm{Nb}$ at about $1373 \mathrm{~K}$ and decreased to room temperature with increasing $\mathrm{Nb}$ concentration (up to 58). This drastic change in the transformation temperature was also found in TiIr. ${ }^{16,17)}$ It is interesting to compare these Ru-based intermetallics and Ti-(Pt,Ir) because the phase transformation temperatures of $\mathrm{Ru}-50 \mathrm{Ta}$ and $\mathrm{Ru}-50 \mathrm{Nb}$ are about 1473 and $1223 \mathrm{~K}$, respectively, and are almost the same as those of Ti-50Pt and $\mathrm{Ti}-50(\mathrm{Pt}, \mathrm{Ir})$. The shape recovery of $\mathrm{Ru}-50 \mathrm{Ta}$ and $\mathrm{Ru}-$ 50Ta by the three-point bending test at 1073 and $1173 \mathrm{~K}$ following reheating at the above transformation temperature was 5 and $4 \%$ of the strain on the tension surface, respectively. ${ }^{11)}$ In the case of the Ti-Pt system, although no shape recovery was found in binary Ti-50Pt by reheating after the loading-unloading compression test, the shape recovery in Ti-25Pt-25Ir was almost the same as those of Ru-based intermetalllics. On the other hand, the shape recovery of $\mathrm{Ru}-50 \mathrm{Ta}$ by deformation dilatometry was $2 \%$ after the sample was compressed to about $4 \%$ strain at $1173 \mathrm{~K}$ and reheated to $1523 \mathrm{~K}$ in the machine. In the case of Ti-50Pt and Ti-50(Pt,Ir), the highest shape recovery obtained using dilatometry was $0.85 \%$ in the ternary $\mathrm{Ti}-50(\mathrm{Pt}, \mathrm{Ir})$, smaller than that in binary $\mathrm{Ru}-50 \mathrm{Ta}$. These results indicate that $\mathrm{Ru}-$ based intermetallics have a better shape memory effect than Ti-(Pt,Ir). However, one disadvantage of Ru-based intermetallics is their brittleness. On the other hand, good ductility is expected in Ti-(Pt,Ir) because Pt is a very ductile material.

\section{Conclusions}

Shape recovery and superelasticity are first demonstrated by thermal expansion measurement and loading-unloading compression tests in Ti-50Pt and Ti- $(50-x) \mathrm{Pt}-\mathrm{xIr}$ ( $\mathrm{X}=$ $12.5,25$, and 37.5$)$. The shape recovery is due to the hightemperature martensitic transformation, which occurs at temperatures from 1273 in $\mathrm{Ti}-50 \mathrm{Pt}$ to $1448 \mathrm{~K}$ in $\mathrm{Ti}-12.5 \mathrm{Pt}-$ 37.5Ir. The highest shape recovery, about $4 \%$ was found in Ti-25Pt-25Ir using loading-unloading compression test. Better superelasticity was obtained in the compounds with higher Ir contents. These results suggest that TiPt and Ti50(Pt,Ir) have a high potential to be high-temperature shape memory alloys.

\section{Acknowledgement}

This work was partially supported by Grants-in-Aid for Fundamental Science Research, (Kiban C: No. 16560620 and Priority Areas 438, No. 17040014) from the Ministry of Education, Culture, Sports, Science and Technology, Japan.

\section{REFERENCES}

1) K. Enami and S. Nenno: Metall. Trans. 2 (1971) 1487-1490.

2) H. Hosoda, M. Tsuji, M. Mimura, Y. Takahashi, K. Wakashima and Y. Yamabe-Mitarai: MRS 753 (2003) BB5-51-1-BB5-51-6.

3) Y. Takahashi, T. Inamura, J. Sakurai, H. Hosoda, K. Wakashima and S. Miyazaki: Trans. MRS-J. 29 (2004) 3005-3008.

4) T. Inamura, Y. Takahashi, H. Hosoda, K. Wakashima, T. Nagase, T. Nakano, Y. Umakoshi and S. Miyazaki: MRS 842 (2004) 347-352.

5) K. Otsuka, K. Oda, Y. Ueno, M. Piao, T. Ueki and H. Horikawa: Scr. Metal. 29 (1993) 1355-1359.

6) D. Golberg, Y. Xu, Y. Murakami, S. Morito, K. Otsuka, T. Ueki and H. Horikawa: Scr. Metal. 30 (1994) 1349-1354.

7) Y. Xu, K. Otsuka, E. Furubayashi, T. Ueki and K. Mitose: Mater. Lett. 30 (1997) 189-197.

8) Y. Xu, S. Shimizu, Y. Suzuki, K. Otsuka, T. Ueki and K. Mitose: Acta Mater. 45 (1997) 1503-1511.

9) Y. Suzuki, Y. Xu, S. Morito, K. Otsuka and K. Mitose: Mater. Lett. 36 (1998) 85-94.

10) S. Shimizu, Y. Xu, E. Okunishi, S. Tanaka, K. Otsuka and K. Mitose: Mater. Lett. 34 (1998) 23-29.

11) R. W. Fonda, H. N. Jones and R. A. Vandermeer: Scr. Mater. 39 (1998) 1031-1037.

12) R. W. Fonda, H. N. Jones and R. A. Vandermeer: Advances in Twinning, Ed. by S. Ankem and C. S. Pande, (TMS, 1999) pp. 279-285.

13) B. H. Chen and H. F. Franzen: J. Less-Common Met. 153 (1989) L13L19.

14) B. H. Chen and H. F. Franzen: J. Less-Common Met. 157 (1990) 3745.

15) R. W. Fonda and R. A. Vandermeer: Philos. Mag A 76 (1997) 119-133.

16) T. B. Massalski: Binary Phase Diagrams, (ASM, Ohio, USA, 1987) p. 2361.

17) T. B. Massalski: Binary Phase Diagrams, (ASM, Ohio, USA, 1987) p. 3142 .

18) T. Biggs, M. J. Witcomb and L. A. Cornish: Mater. Sci. Eng. A 273275 (1999) 204-207.

19) T. Biggs, M. B. Cortie, M. J. Witcomb and L. A. Cornish: Mater. Trans. A 32A (2001) 1881-1886.

20) Y. Yamabe-Mitarai, T. Hara and H. Hosoda: Mater. Sci. Forum 426432 (2003) 2267-2272.

21) T. Hara and Y. Yamabe-Mitarai: Collected Abstracts of the 2003 Autumn Meeting of the Japan Inst. Metals (2003) 87.

22) Y. Yamabe-Mitarai, T. Hara, S. Miura and H. Hosoda: J. Jpn. Inst. Met. 69 (2005) 634-642. 